\title{
ANALISIS TINGKAT PELAYANAN JASA MENGGUNAKAN METODE SERVICE QUALITY (SERVQUAL)-FUZZY DI INSTALASI RAWAT INAP KELAS III SUATU RUMAH SAKIT
}

\section{Dicky Suryapranatha}

\author{
Program Studi Teknik Industri Universitas Buana Perjuagan Karawang \\ Jl. HS. Ronggo Waluyo, Telukjambe Timur, Karawang \\ dicky.suryapranatha@ubpkarawang.ac.id
}

\begin{abstract}
Abstrak
Pengukuran suatu jasa kepada konsumennya. Penelitian ini dilakukan di Instalasi Rawat Inap Kelas III pada sebuah Rumah Sakit mengunakan beberapa responden dari pasien. Menggunakan metode servqual dengan pendekatan Fuzzy terhadap lima dimensi kualitas jasa yaitu Tangibles, Reliability, Responsiveness, Assurance, dan Emphaty.

Hasil penelitian menunjukkan terdapat gap antara persepsi pasien dengan harapan pasien yaitu sebesar -0,511.perbedaan ini menjadi prioritas untuk dilakukannya perbaikan adalah dimensi kualitas Reliability karena memiliki nilai gap terbesar yaitu -0,657.
\end{abstract}

Kata kunci : Kualitas Pelayanan, Metode Servqual, Metode Fuzzy, Rawat Inap Reliability

\section{Abstract}

The level of service quality is a parameter of the success or failure of a service provided to customers. This research was conducted in Inpatient Class III at a General Hospital . Respondents involved amounted to 40 respondents. This study using methods servqual with Fuzzy method approach to the five dimensions of service quality is Tangible, Reliability, Responsiveness, Assurance, and Empathy. The results showed a gap between the perceptions of patients with the expectation of patients that is equal to -0.511. And that should be a priority to undertake an improvement is the quality dimensions of Reliability because it has the biggest gap is -0.657 .

Keywords : Service Quality, Servqual Method, Fuzzy Method, Inpatient, Reliability 


\section{PENDAHULUAN}

Perkembangan ilmu dan teknologi kesehatan sudah berkembang sangat pesat di era globalisasi saat ini. Dengan dilakukannya berbagai penelitian dari masa ke masa oleh para ahli, bidang kesehatan sudah berkembang ke arah industri. Industri di bidang kesehatan ini erat sekali kaitannya dengan industri jasa karena di dalamnya pelayanan merupakan produk yang diberikan kepada konsumennya. Pada awalnya ilmu dibidang kesehatan hanya untuk kepentingan kemanusiaan/sosial, dan setelah berkembang menjadi sebuah industri kualitas pelayan menjadi aspek yang terus diperhatikan oleh para pelaku industri di dalamnya.

Usaha pendefinisian dan pengukuran kualitas telah semakin banyak dilakukan. Untuk produk berupa barang, konsumen dapat secara mudah mengukur dan menilai kualitas produk sebuah barang dengan melihat bentuk, warna, kemasan, atau dengan merasakan dan mencium baunya, akan tetapi pada pengukuran kualitas jasa sulit untuk diterapkan cara yang sama. Hal ini oleh Parasuraman dkk (1994), disebabkan oleh karakteristik produk jasa/pelayanan itu sendiri yang intangibility (bahwa jasa bersifat tidak terlihat, bukan sebuah objek melainkan sebuah kinerja), heterogenity (jasa diselenggarakan oleh beberapa orang yang kinerjanya berbeda satu sama lain sehingga konsistensi pelayanan mereka berbeda dari waktu ke waktu) dan inseparibility (produksi dan konsumsi pada jasa tidak dapat dipisahkan, jasa dinilai pada saat proses penghantaran pelayanan dilakukan) yang harus benarbenar dipahami dalam penilaian kualitas jasa/pelayanan.

Kehadiran sebuah Rumah Sakit di Karawang mendorong setiap rumah sakit tersebut untuk ikut dalam persaingan yang semakin ketat. Disamping itu tingkat kesadaran masyarakat akan kualitas pelayanan kesehatan yang semakin tinggi membuat rumah sakit akan berusaha untuk meningkatkan kualitasnya. Pelayanan kesehatan yang profesional serta kenyamanan yang dirasakan keluarga yang berada di dekat pasien akan membantu pulihnya kesehatan pasien. Hal ini sangat penting terutama bagi pasien yang menjalani pengobatan rawat inap. 
Konsep Fuzzy - servqual adalah sebuah teori pengukuran yang mengakomodir bahasa linguistik dengan bahasa numerik (angka/statistik). Faktor ketidakpresisian telah diakomodasi dalam sebuah penilaian variabel linguistik yang mengadaptasi ketidakpresisian data, ambiguitas dan subjektifitas, yang tidak dapat dilakukan dengan model servqual biasa. (Kusumadewi, 2010). Metode fuzzy - servqual digunakan untuk menyelesaikan permasalahan di suatu Rumah Sakit tentang penilaian kualitas pelayanan terutama di Instalasi Rawat Inap Kelas III sehingga tercipta kualitas pelayanan yang lebih baik di masa yang akan datang.

\section{METODE PENELITIAN}

Variabel-variabel yang digunakan dalam penelitian ini meliputi :

\section{Variabel Terikat}

Yaitu variabel yang nilainya tergantung dari variasi perubahan variabel bebas. Variabel yang diteliti adalah kepuasan pelanggan berdasarkan pelayanan yang diberikan. Kualitas pelayanan di Rumah Sakit yang diukur berdasarkan kepuasan pasien pada Instalasi Rawat Inap Kelas III.

Pengukuran variabel tersebut berdasarkan tanggapan responden terhadap pertanyaan-pertanyaan dalam kuesioner yang skornya ditetapkan menggunakan skala penilaian, yaitu pemberian bobot (skor) terhadap respon dari pasien dalam bentuk himpunan fuzzy (Zadeh, 1965) yang terdiri dari 5 kategori sebagai berikut ini :
a. Kategori 1 : Sangat Tidak Baik dengan skor 1,2,3
b. Kategori 2 : Tidak Baik dengan skor 2,3,4
c. Kategori 3 : Cukup Baik dengan skor 3,4,5
d. Kategori 4 : Baik dengan skor 4,5,6
e. Kategori 5 : Sangat Baik dengan skor 5,6,7 


\section{Variabel Bebas}

Yaitu variabel yang mempengaruhi variasi perubahan nilai variabel terikat. Dalam hal ini variabel yang digunakan adalah berupa alat untuk mengukur kualitas pelayanan atau yang biasa disebut "Servqual" (Parasuraman, 1994) yang meliputi Tangibles (bukti fisik) yaitu Berkenaan dengan daya tarik fasilitas fisik, perlengkapan, dan material yang digunakan perusahaan, serta penampilan karyawan, Reliability (keandalan) yaitu kemampuan perusahaan untuk memberikan layanan yang akurat sejak pertama kali tanpa membuat kesalahan apapun dan menyampaikan jasanya sesuai dengan waktu yang disepakati, Responsiveness (daya tanggap) yaitu menunjukkan kemampuan perusahaan dalam memberikan respon kepada pelanggan, Assurance (jaminan) yaitu menunjukkan kemampuan perusahaan dalam menumbuhkan kepercayaan dan keyakinan pada pelanggan, Emphaty (empati) yaitu menunjukkan tingkat kepedulian dan perhatian perusahaan kepada pelanggan.

\section{HASIL DAN PEMBAHASAN}

\section{Uji Kecukupan Data}

Ukuran sampel minimum dalam penelitian ini ditentukan dengan menggunakan rumus Bernoulli sebagai berikut:

$$
\begin{aligned}
n & =\left(\frac{Z_{\alpha / 2}}{e}\right)^{2} \times p \times q \\
& =\left(\frac{1,96}{0,05}\right)^{2} \times(39 / 40) \times(1 / 40) \\
& =1536,64 \times 0,975 \times 0,025 \\
& =37,4556 \approx 37 \text { Kuesioner }
\end{aligned}
$$

Dengan menggunakan taraf keberartian sebesar 95\% (dari tabel $\mathrm{F}$ nilai $\left.\mathrm{Z}_{(0,95 / 2)}=1,96\right)$ dan nilai kesalahan sebesar $5 \%$ maka didapat sampel minimum sebanyak 37 responden dan untuk kuisoner sudah diambil sebanyak 40 orang. 


\section{Rekapitulasi Data Persepsi dan Data Harapan Pasien}

Tabel 1 Rekapitulasi data persepsi pasien

\begin{tabular}{|c|c|c|c|c|c|c|}
\hline No. & Kriteria & $\begin{array}{l}\text { Sangat } \\
\text { Tidak } \\
\text { Baik } \\
\text { (1) }\end{array}$ & $\begin{array}{l}\text { Tidak } \\
\text { Baik } \\
(2) \\
\end{array}$ & $\begin{array}{l}\text { Kurang } \\
\text { Baik } \\
(3)\end{array}$ & $\begin{array}{l}\text { Baik } \\
\text { (4) }\end{array}$ & $\begin{array}{l}\text { Sangat } \\
\text { Baik } \\
(5)\end{array}$ \\
\hline 1 & $\begin{array}{l}\text { Kemudahan mencapai lokasi Instalasi } \\
\text { Rawat Inap kelas III }\end{array}$ & 0 & 0 & 0 & 31 & 8 \\
\hline 2 & $\begin{array}{l}\text { Kebersihan, kerapian dan } \\
\text { kenyamanan kamar }\end{array}$ & 0 & 0 & 5 & 31 & 3 \\
\hline 3 & Kebersihan kamar mandi & 0 & 2 & 2 & 30 & 5 \\
\hline 4 & Luas area dan fasilitas kamar & 0 & 2 & 12 & 24 & 1 \\
\hline 5 & $\begin{array}{l}\text { Ketersediaan obat yang dibutuhkan } \\
\text { pasien }\end{array}$ & 0 & 0 & 1 & 30 & 8 \\
\hline 6 & $\begin{array}{l}\text { Kebersihan peralatan makan dan } \\
\text { makanan yang disajikan }\end{array}$ & 0 & 0 & 0 & 27 & 12 \\
\hline 7 & $\begin{array}{l}\text { Tempat tidur telah disiapkan dalam } \\
\text { keadaan rapi, bersih \& siap pakai }\end{array}$ & 0 & 2 & 5 & 27 & 5 \\
\hline 8 & $\begin{array}{l}\text { Kerapian dan kebersihan penampilan } \\
\text { dokter dan perawat }\end{array}$ & 0 & 0 & 1 & 28 & 10 \\
\hline 9 & Penerangan di kamar & 0 & 0 & 4 & 24 & 11 \\
\hline 10 & $\begin{array}{l}\text { Ketersediaan tempat sampah di depan } \\
\text { kamar }\end{array}$ & 0 & 2 & 5 & 30 & 2 \\
\hline 11 & $\begin{array}{l}\text { Pelayanan pemeriksaan, pengobatan } \\
\text { dan perawatan yang cepat dan tepat }\end{array}$ & 0 & 1 & 8 & 22 & 8 \\
\hline 12 & $\begin{array}{l}\text { Kesiapan dokter \& perawat melayani } \\
\text { pasien setiap saat }\end{array}$ & 0 & 3 & 3 & 26 & 7 \\
\hline 13 & $\begin{array}{l}\text { Prosedur penerimaan pasien dilayani } \\
\text { dengan cepat } \& \text { tidak berbelit-belit }\end{array}$ & 0 & 0 & 1 & 32 & 6 \\
\hline 14 & $\begin{array}{l}\text { Dokter \& perawat selalu menanyakan } \\
\text { keluhan pasien }\end{array}$ & 0 & 0 & 2 & 25 & 12 \\
\hline 15 & $\begin{array}{l}\text { Dokter \& perawat memberikan } \\
\text { kesempatan bertanya kepada pasien }\end{array}$ & 0 & 0 & 5 & 27 & 7 \\
\hline 16 & $\begin{array}{l}\text { Dokter memberi penjelasan tentang } \\
\text { penyakit }\end{array}$ & 0 & 0 & 8 & 26 & 5 \\
\hline 17 & $\begin{array}{l}\text { Memberi jaminan akan kesembuhan } \\
\text { pasien }\end{array}$ & 0 & 0 & 5 & 29 & 5 \\
\hline 18 & $\begin{array}{l}\text { Kemampuan dokter menganalisis } \\
\text { penyakit }\end{array}$ & 0 & 3 & 1 & 24 & 11 \\
\hline 19 & $\begin{array}{l}\text { Keramahan dan kesopanan dokter, } \\
\text { perawat dan karyawan rumah sakit }\end{array}$ & 0 & 0 & 4 & 25 & 10 \\
\hline
\end{tabular}


Dokter berusaha menenangkan rasa

20 cemas pasien terhadap penyakit yang diderita

Perawat selalu mengingatkan

21 keamanan akan menyimpan barang 0

berharga pasien dan keluarganya

Sumber : Data Primer Tahun 2016

Tabel 2 Rekapitulasi data harapan pasien

\begin{tabular}{|c|c|c|c|c|c|c|}
\hline No. & Kriteria & $\begin{array}{l}\text { Sangat } \\
\text { Tidak } \\
\text { Penting } \\
\text { (1) }\end{array}$ & $\begin{array}{l}\text { Tidak } \\
\text { Penting } \\
(2)\end{array}$ & $\begin{array}{l}\text { Kurang } \\
\text { Penting } \\
(3)\end{array}$ & $\begin{array}{l}\text { Penting } \\
(4)\end{array}$ & $\begin{array}{l}\text { Sangat } \\
\text { Penting } \\
(5)\end{array}$ \\
\hline 1 & $\begin{array}{l}\text { Kemudahan mencapai lokasi Instalasi } \\
\text { Rawat Inap kelas III }\end{array}$ & 0 & 0 & 1 & 22 & 16 \\
\hline 2 & $\begin{array}{l}\text { Kebersihan, kerapian dan kenyamanan } \\
\text { kamar }\end{array}$ & 0 & 0 & 1 & 16 & 22 \\
\hline 3 & Kebersihan kamar mandi & 0 & 0 & 1 & 19 & 19 \\
\hline 4 & Luas area dan fasilitas kamar & 0 & 0 & 3 & 17 & 19 \\
\hline 5 & $\begin{array}{l}\text { Ketersediaan obat yang dibutuhkan } \\
\text { pasien }\end{array}$ & 0 & 0 & 1 & 17 & 21 \\
\hline 6 & $\begin{array}{l}\text { Kebersihan peralatan makan dan } \\
\text { makanan yang disajikan }\end{array}$ & 0 & 0 & 0 & 17 & 22 \\
\hline 7 & $\begin{array}{l}\text { Tempat tidur telah disiapkan dalam } \\
\text { keadaan rapi, bersih \& siap pakai }\end{array}$ & 0 & 0 & 0 & 20 & 19 \\
\hline 8 & $\begin{array}{l}\text { Kerapian dan kebersihan penampilan } \\
\text { dokter dan perawat }\end{array}$ & 0 & 0 & 2 & 25 & 12 \\
\hline 9 & Penerangan di kamar & 0 & 0 & 0 & 26 & 13 \\
\hline 10 & $\begin{array}{l}\text { Ketersediaan tempat sampah di depan } \\
\text { kamar }\end{array}$ & 0 & 0 & 1 & 19 & 19 \\
\hline 11 & $\begin{array}{l}\text { Pelayanan pemeriksaan, pengobatan dan } \\
\text { perawatan yang cepat dan tepat }\end{array}$ & 0 & 0 & 0 & 9 & 30 \\
\hline 12 & $\begin{array}{l}\text { Kesiapan dokter \& perawat melayani } \\
\text { pasien setiap saat }\end{array}$ & 0 & 0 & 0 & 12 & 27 \\
\hline 13 & $\begin{array}{l}\text { Prosedur penerimaan pasien dilayani } \\
\text { dengan cepat } \& \text { tidak berbelit-belit }\end{array}$ & 0 & 0 & 0 & 19 & 20 \\
\hline 14 & $\begin{array}{l}\text { Dokter \& perawat selalu menanyakan } \\
\text { keluhan pasien }\end{array}$ & 0 & 0 & 0 & 18 & 21 \\
\hline 15 & $\begin{array}{l}\text { Dokter \& perawat memberikan } \\
\text { kesempatan bertanya kepada pasien }\end{array}$ & 0 & 0 & 2 & 24 & 13 \\
\hline 16 & $\begin{array}{l}\text { Dokter memberi penjelasan tentang } \\
\text { penyakit }\end{array}$ & 0 & 0 & 1 & 16 & 22 \\
\hline
\end{tabular}




\begin{tabular}{lllllll}
17 & $\begin{array}{l}\text { Memberi jaminan akan kesembuhan } \\
\text { pasien }\end{array}$ & 0 & 0 & 0 & 16 & 23 \\
\hline 18 & $\begin{array}{l}\text { Kemampuan dokter menganalisis } \\
\text { penyakit }\end{array}$ & 0 & 0 & 16 & 23 \\
\hline 19 & $\begin{array}{l}\text { Keramahan dan kesopanan dokter, } \\
\text { perawat dan karyawan rumah sakit }\end{array}$ & 0 & 1 & 12 & 26 \\
\hline 20 & $\begin{array}{l}\text { Dokter berusaha menenangkan rasa } \\
\text { cemas pasien terhadap penyakit yang } \\
\text { diderita }\end{array}$ & 0 & 0 & 17 & 22 \\
\hline 21 & $\begin{array}{l}\text { Perawat selalu mengingatkan keamanan } \\
\text { akan menyimpan barang berharga pasien } \\
\text { dan keluarganya }\end{array}$ & 0 & 1 & 21 & 17 \\
\hline
\end{tabular}

Sumber : Data Primer Tahun 2016

\section{Analisis Perhitungan Nilai Servqual (Gap) Per Dimensi}

Dari hasil perhitungan nilai Servqual (gap) per dimensi, yang menempati ranking pertama adalah dimensi Reliability sebesar -0,657, untuk urutan kedua yaitu dimensi Emphaty sebesar -0,563, urutan ketiga yaitu dimensi Assurance sebesar -0,545, urutan keempat yaitu dimensi Tangibles sebesar -0,410, dan yang terakhir atau urutan kelima yaitu Responsiveness sebesar $-0,381$.

Gambar 1 Persentase nilai servqual (gap) per dimensi

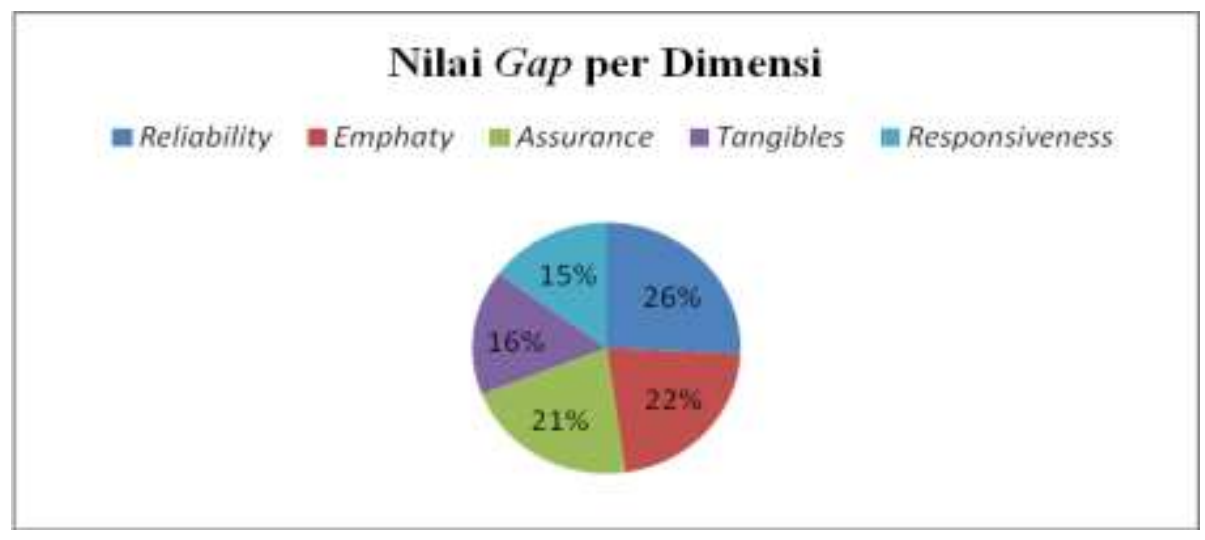

\section{Analisis Perhitungan Nilai Servqual (Gap) Per Kriteria}


Dari hasil perhitungan nilai servqual (gap) per kriteria diperoleh lima kriteria yang perlu menjadi prioritas untuk dilakukan perbaikan dan peningkatan kualitas pelayanan seperti pada tabel di bawah ini :

Tabel 3 Nilai servqual per kriteria terbesar

\begin{tabular}{llcc}
\hline No. & Kriteria & $\begin{array}{l}\text { Nilai } \\
\text { Servqual }\end{array}$ & Rank \\
\hline 1 & $\begin{array}{l}\text { Pelayanan pemeriksaan, pengobatan dan perawatan yang } \\
\text { cepat dan tepat }\end{array}$ & -0.830 & 1 \\
\hline 2 & Luas area dan fasilitas kamar & -0.806 & 2 \\
\hline 3 & Kesiapan dokter \& perawat melayani pasien setiap saat & -0.753 & 3 \\
\hline 4 & $\begin{array}{l}\text { Perawat selalu mengingatkan keamanan akan menyimpan } \\
\text { barang berharga pasien dan keluarganya }\end{array}$ & -0.676 & 4 \\
\hline 5 & Ketersediaan tempat sampah di depan kamar & -0.649 & 5 \\
\hline
\end{tabular}

\section{KESIMPULAN}

Berdasarkan pengolahan data tingkat kualitas pelayanan di Instalasi Rawat Inap Kelas III masih belum terpenuhi. Hal tersebut dapat ditunjukkan dari nilai servqual (gap) secara keseluruhan yang bernilai negatif yaitu sebesar -0,511. Artinya pelayanan yang diterima masih lebih rendah dari pelayanan yang diharapkan oleh pasien pada Instalasi Rawat Inap Kelas III. Maka dari itu harus adanya suatu perbaikan terhadap kriteria-kriteria yang mempengaruhi tingkat kualitas pelayanan instalasi rawat inap kelas III, sehingga dengan harapan dapat tercipta peningkatan kualitas pelayanan di masa yang akan datang.

Faktor-faktor jasa yang paling mempengaruhi atas ketidakpuasan pasien terhadap pelayanan pada Instalasi Rawat Inap Kelas III adalah Pelayanan pemeriksaan, pengobatan dan perawatan yang cepat dan tepat $\left(\mathrm{X}_{11}\right)$, dengan nilai servqual (gap) sebesar -0,830. Luas area dan fasilitas kamar $\left(\mathrm{X}_{4}\right)$, dengan nilai servqual (gap) sebesar -0,806. Kesiapan dokter dan perawat $\left(\mathrm{X}_{12}\right)$, dengan nilai servqual (gap) sebesar -0,753. Perawat selalu mengingatkan keamanan $\left(\mathrm{X}_{21}\right)$, dengan nilai servqual (gap) sebesar -0,676. Ketersediaan tempat sampah $\left(\mathrm{X}_{10}\right)$, dengan nilai servqual (gap) sebesar -0,649. 


\section{DAFTAR PUSTAKA}

Aisyati, Azizah dkk. (2007). Analisa Kualitas Pelayanan Rumah Sakit Umum Daerah (RSUD) Wonogiri Menggunakan Metode Fuzzy-Servqual. Jurnal pada Program Studi Teknik Industri Fakultas Teknik, Universitas Sebelas Maret, Surakarta

Azwar, Azrul. (1988). Pengantar Administrasi Kesehatan. Jakarta : PT. Binarupa Aksara.

Dawai Simfoni, 2014 Pengujian Validitas dan Reliabilitas Skor Kuesioner, https://dawaisimfoni.wordpress.com/karya-tulis-ilmiah-2/metodologipenelitian/pengujian-validitas-reliabilitas-skor-kuesioner/

Dedy Londong, 2011 Dasar Penentuan Jumlah Sampel Penelitian, http://dedylondong.blogspot.co.id/2011/10/dasar-penentuan-jumlahsample.html

Muna, Nailil. 2007. Usulan Perbaikan Kualitas Pelayanan Rawat Inap Rumah Sakit Islam Surakarta Menggunakan Model ServQual dan Analisis Faktor. Skripsi pada Program Studi Teknik Industri, Universitas Sebelas Maret, Surakarta.

Olfa, Maria. 2005. "Peningkatan Kualitas Pelayanan Jasa Kesehatan Di Instalasi Rawat Inap Dengan Menggunakan Metode Servqual-Fuzzy". Skripsi pada Program Studi Teknik Industri, Universitas Pembangunan Nasional "Veteran", Jawa Timur.

Priyadi, Eddy. Penentuan Kepuasan Pasien Rawat Inap Rumah Sakit Umum Daerah Dengan Metode Logika Fuzzy. Jurnal pada Program Studi Manajemen Informatika, STMIK Widya Pratama, Pekalongan.

Sudaryono. (2014). Perilaku Konsumen Dalam Perspektif Pemasaran. Jakarta : Lentera Ilmu Cendekia.

Suharyanta, Dwi dan A’yunin Qurrota. 2011. Analisis Tingkat Kualitas Pelayanan Jasa Menggunakan Metode Service Quality (ServQual) Fuzzy Di Instalasi Radiologi Rumah Sakit Umum Daerah Panembahan Senopati Bantul. Jurnal pada Program Studi Kesehatan Masyarakat, STIKES Surya Global, Yogyakarta.

Sujarweni, V. Wiratna. (2015). SPSS Untuk Penelitian. Yogyakarta : Penerbit Pustaka Baru Press.

Tjiptono, Fandy. (2016). Service, Quality dan Satisfaction. Yogyakarta : Penerbit Andi Offset 
Wibowo, Ibnu Teguh. (2014). Belajar Formula \& Fungsi Microsoft Excel. Yogyakarta : Notebook

Yamit, Zulian. (2013). Manajemen Kualitas Produk \& Jasa. Yogyakarta : Penerbit Ekonisia. 